\title{
Implementation of Personalized Adaptive E-learning System
}

\author{
Vija VAGALE $^{1,2}$, Laila NIEDRITE ${ }^{1}$, Svetlana IGNATJEVA ${ }^{2}$ \\ ${ }^{1}$ Faculty of Computing, University of Latvia, Raina Boulv.19, Riga, LV-1586, Latvia \\ ${ }^{2}$ Faculty of Natural Sciences and Mathematics, Daugavpils University, \\ Vienibas 13 St., Daugavpils, LV-5401, Latvia \\ vija.vagale@gmail.com, laila.niedritedlu.lv, \\ svetlana.ignatjeva@du. Iv
}

\begin{abstract}
Open source learning management systems have been widely used in the learning process. However, they do not include options for learning content and process adaptation and personalization. The aim of the paper is to propose an architecture of a learner model based personalized adaptive system. The development of the system proposed in the paper is based on learning management system Moodle. The system is described with the help of such models as a learner model, a content model and an adaptation model. The learner model described the learner in the context of lifelong learning. The content model is based on the vast variety of resources and activities. The adaptation of the system is based on the learner characterizing features and the variety of course topic acquisition sequences. The results of the developed system approbation show that the system is especially suitable for "sensitive" learner category. This category includes learners with the following features: first study year female students with general secondary education, average level of information technology competence, with learning management systems usage experience and Moodle usage experience less than a year.
\end{abstract}

Keywords: System, architecture, implementation, e-learning, adaptation, personalization

\section{Introduction}

With the rhythm of life becoming more intense, the necessity for new and effective solutions in different scopes of people's activity arises including the field of education. One of the actual tasks for improving the quality of education is the utilization of elearning systems. E-learning systems are a modern and convenient type of tuition with high efficiency, which is based on computer and network utilization for learning requirements (Vassileva, 2012). They include active employment of information and communication technologies (ICT) to promote and modify the learning process (Riad et al., 2009). Scheuermann and Pedró (2010) emphasize that "ICT is a tool for the support of personalisation strategies in teaching and learning".

The learning process encounters several challenges: (i) the amount of the information to be acquired increases (i.e. information overload problem), (ii) the necessity for the lifelong learning increases, (iii) the necessity for the professional reorientation and the self-learning increases, (iv) the use of ICT in the education including e-learning for 
providing the learning process grows, (v) different attitude towards the use of ICT can be observed in the society (digital natives and digital immigrants (Prensky, 2001)), (vi) the necessity for the more individualized learning approach increases (WEB, b), (vii) the necessity for the "all individuals to learn, anywhere, anytime, through any device, with the support of anyone" (WEB, a).

Above-mentioned tendencies highlight the problem that widely used e-learning environments could be effectively adapted to the learner's needs in order to ensure qualitative and convenient (for learner) learning process.

When providing various learning strategies in the system, it is important to pay attention to how the interaction between the learner and the system is organized. In case of the customized system, the learner indicates how the system should adapt. In case of the adaptive system, the system on its own indicated the type of adaptation. Analysis of the previous research (Caputi and Garrido, 2015; Alshammari et al., 2015; Tosheva et al., 2017; Ahmed et al., 2018) shows that the existing approaches for learner group and learning path organization could be improved, thus gaining wider range of system adaptation options. As the result, a Learner Model based Personalized Adaptive eLearning System (LMPAELS) was developed. Learner groups used for adaptation organization are created by the course teacher and they are valid within one specific course. The learning path creation in the offered system is performed at the course topic level with an option to choose between different learning topic sequences.

The architecture of the system proposed in the paper is based on three models: a learner model, a content model, and an adaptation model. learner model describes an adult learner and is applicable to the lifelong learning. Content model supports the use of various learning resource formats. The system implements (i) the adaptation of the course structure, (ii) the adaptation of the course content, and (iii) the adaptability of the acquired topic sequence. The proposed system architecture was experimentally tested. The results of the experimentation confirm the utility and appropriateness of the proposed system for a specific target audience.

The previous scientific paper by the authors (Vagale et al., 2018) gives an overview of the architecture of the developed personalized adaptive system whereas the current paper is the extended version of the previous article. The current paper gives more detailed description of the developed system, it includes the description of the developed models implementation and provides a wider explanation on the experiment and evaluation of its results.

The remainder of the paper is structured as follows. Section 2 presents related work. Section 3 describes the components of the system architecture. Section 4 describes the system implementation. Section 5 presents the experiment of the system approbation and obtained results evaluation. Discussion on the use of the developed system is given in Section 6. Finally, conclusions and future work are given in Section 7.

\section{Related Work}

Many papers have been dedicated to the adaptation of e-learning and these studies have a long history, but with the development of technology and the needs of society, new opportunities are emerging. Four latest and most relevant approaches were chosen to characterize the novelty and capabilities of the proposed system.

The authors in (Ahmed et al., 2018) describe the adaptive e-learning model that consists of four components: a content model, a learner model, an adaptive model, and a 
communication interface (for the communication between the learner and the system). The content model is based on the Shareable Content Object Reference Model (SCORM). The course consists of chapters, where chapters contain lessons, animations, and exercises that use assets and sharable content objects from SCORM. Each chapter is created according to three levels of complexity (level-1, level-2, level-3). Three stereotypes are used to classify learner: novice, intermediate, and expert. The learner is offered content (chapters) of the corresponding difficulty level depending on the stereotype assigned to him (level-1 for the novice, level-2 for the intermediate and level3 for the expert learners). The acquisition of each topic is assessed using a quiz. In (Ahmed et al., 2018), the emphasis is on the automatic allocation and change of stereotypes depending on the results of the quizzes.

Another study (Alshammari et al., 2015) describes adaptive e-learning system "AdaptLearn" using three main models: a domain model, a learner model, and an adaptation model. Additional components are interaction module (for communication between the learner and the system) and data modeller (for learner model data update). The domain model consists of instructional units that contain learning object. All learning objects are divided into two groups: abstract learning objects (include concepts, mathematical notations) and concrete learning objects (include examples and practical tools). Depending on the learning style, all learners are divided into two groups: (1) sensing and (2) intuitive learners. In (Alshammari et al., 2015), the emphasis is placed on the automatic adaptation of the learning path based on the learner's learning style. For sensing learners, a specific learning object is given first and an abstract learning object is given afterwards. For intuitive learners, it is the other way around - the first is an abstract learning object, followed by a specific learning object.

The authors in (Tosheva et al., 2017) describe the adaptive learning system "Eschool". Learner groups are created by the system administrator based on the characteristics of learners. Different learner groups have access to specific lectures. In (Tosheva et al., 2017), the emphasis is on the ability of learners to monitor their own learning progress and to improve it. Teachers are able to assess the progress of a learner. A tree of lectures is created for each learner and their knowledge is assessed using a quiz that can be completed several times. The same content may have different quizzes generated.

The best sequence of the course learning activities is offered by authors in (Caputi and Garrido, 2015). The sequence is based on the correspondence between learner characteristics (background knowledge and learning objectives) and course activities defined in the system.

The aforementioned approaches have some common features: (i) the systems are based on three main models: the content or domain model, the learner model and the adaptation model; (ii) learner groups are implemented to ensure adaptation; (iii) there is a relationship between the structure of the learner model and content model. These features can also refer to the system proposed in this paper.

The literature review shows that the existing methods have following shortcomings: (i) learner groups are defined by the system administrator (Alshammari et al., 2015; Tosheva et al., 2017; Ahmed et al., 2018) and (ii) the learning path is created within one learning object (Alshammari et al., 2015) or one topic (Caputi and Garrido, 2015).

Based on these drawbacks, the LMPAELS system that extends the functionality of adaptation, was proposed in this paper. In LMPAELS system, proposed in this paper, learner groups are created by the course creator or a teacher. This approach ensures that 
each course has its own learner groups and the creation of the learner groups considers not only the learner characterizing data, but also the pedagogical experience of a teacher and the course features. LMPAELS system has implemented learning path creation at the course topic level. The learner has the opportunity to make multiple choices between three topic sequences: the teacher topic sequence, the optimal topic sequence, and the learner topic sequence.

\section{Components of the System Architecture}

This section describes the conceptual architecture of the developed system. The structure of the LMPAELS system is described with the help of models. The model is a simplified representation of the real world, which includes only the problem-related variables (Hart, 2015). LMPAELS is based on three models: a learner model, a content model, and an adaptation model (see Figure 1. Architecture of the main components of the system LMPAELSFigure 1).

The learner model contains data about the learner in the system. The content model includes the content offered by the system and its logical structure. The adaptation model describes conditions and rules used in the adaptation.

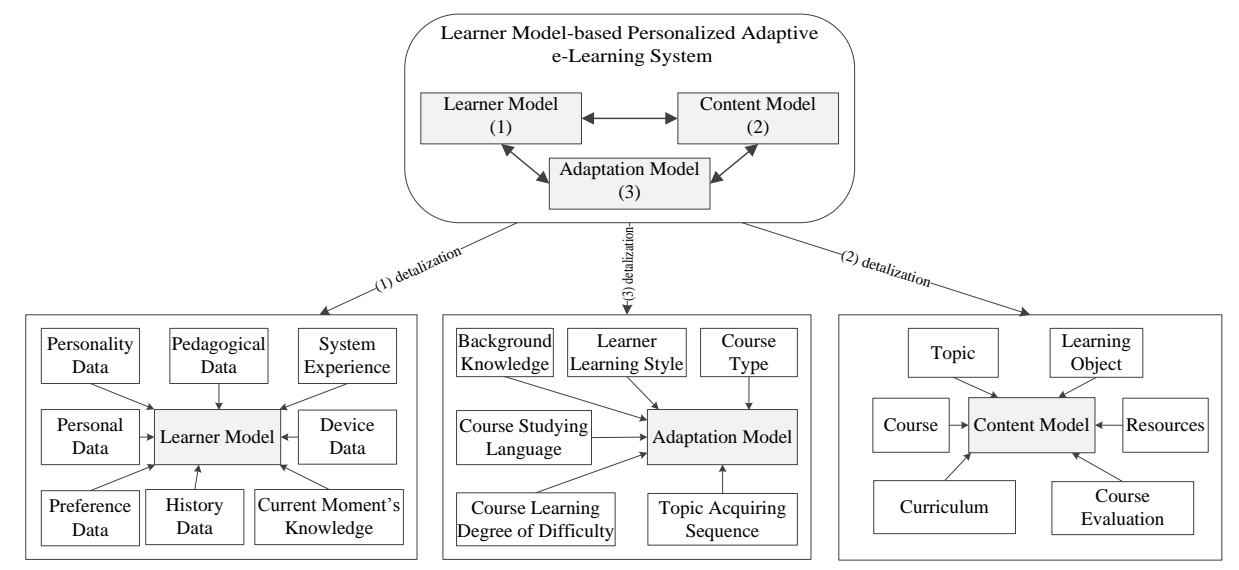

Figure 1. Architecture of the main components of the system LMPAELS.

\subsection{Learner Model}

Learner model in the LMPAELS system describes the adult as a learner. Learner model is used in the context of lifelong learning. The system's learner characterizing data are divided into eight data categories: personal data, personality data, pedagogical data, preference data, device data, system experience, current moment's knowledge, and history data (see Figure 1). The choice of data categories for the learner model is based on the results published in (Vagale and Niedrite, 2012).

As learner model describes the learner in the lifelong context according to the data lifetime in the system the learner data are divided into three big groups: (i) basic data; (ii) additional data, and (iii) learning process data. 
The basic data include data values which do not change over time, like personal data. The additional data include data values which tend to change over a longer period of time. This group includes data from the following categories: personality data, pedagogical data, preference data, system experience, and device data. The learning process data include data values of which are constantly changing, like history data and current moment knowledge.

The data categories used in the learner model are described in the paper (Vagale and Niedrite, 2012). The complete learner model description can be found in the paper (Vagale and Niedrite, 2014). The learner model implementation is described in the Section 4.2.

\subsection{Content Model}

The content model of the LMPAELS system is based on the use of learning object and various resource formats. Learning object represent the learning materials as separate, small, independent units that can be reused in different situations in different parts of the study material (Allen and Mugisa, 2010).

A learning course of the offered LMPAELS content model consists of one or more topics (see Figure 1). Each topic consists of one or more learning objects, where each learning object consists of four parts: description part, theoretical part, practical part, and evaluation part.

The description part explains the essence of the particular learning object, its tasks and place in the course structure. The theoretical part contains the provided knowledge for learning, where the knowledge is represented using activities and resources. The practical part contains activities aimed at strengthening the acquired knowledge. The evaluation part contains activities that are used to assess the knowledge acquired by a learner such as a task/quiz.

A complete description of the LMPAELS content model can be found in (Vagale and Niedrite, 2014). Practical implementation of the content model is described in Section 4.3 .

\subsection{Adaptation Model}

The adaptation model describes adaptation methods implemented in the system and methods used for adaptation. The LMPAELS system is used for adaptation of (i) the course structure, (ii) the course content, and (iii) the course topic sequence (see Figure $6)$.

Adaptation of the course structure (Course Type) (see Figure 1) is performed using different parts of the learning object of the created content model. The system has both practical and theoretical courses. All four learning object's parts are used building the structure of the practical course. The structure of the theoretical course contains only three learning object's parts (excluding the practical part of the learning object).

Adaptation of the course content is based on the (a) learner learning style, (b) course background knowledge, and (c) chosen course learning degree of difficulty (see Figure $1)$.

The learning style determines displayed learning resources in the theoretical part of the learning object. This learning object's part uses resources types like visual, aural, read, kinaesthetic, and a combination of the visual-aural learning style. 
The existence or absence of learner pre-knowledge of the particular course determines whether additional explanations in the learning object's theoretical part are shown.

The degree of difficulty of the course acquisition chosen by the learner determines the difficulty level of assignments/quizzes that are being offered to the learner and the maximum grade that the learner can receive upon finishing the course. Three levels of the course acquisition difficulty are realized in the system: (i) the lowest level - grades 1 to 6 inclusively, (ii) the average level - grades 7 to 8 inclusively, and (iii) the highest level - grades 9 to 10 inclusively (see Figure 6). The choice of the above-mentioned degrees of difficulty in based on the assessment system adopted in the Latvian education system, the pedagogical experience of the authors, and the desires of learners.

Learner groups are used to ensure the adaptation of the course content for which the appropriate adaptation scenarios are created in the system. Learner group classification method is designed for the learner groups creation. Learner groups are created using the learner feature tree. A more complete description of the learner group classification method and adaptation scenarios are presented in the paper (Vagale and Niedrite, 2014).

The inclusion of learners in a group is performed with the learner group identificator searching algorithm made with the purpose to find the most suitable learner group for the learner. The algorithm is based on the highest value of the learner characteristics and matching values with the learner group feature. The learner group classification method is described in the paper (Vagale and Niedrite, 2014).

The use of the variants for the course topics acquisition sequence (Topic Acquiring Sequence) (see Figure 1) gives a learner the opportunity to choose one of three topic sequences: (a) a teacher-proposed topic sequence, (b) learner topic sequence, or (c) optimal topic sequence.

Teacher topic sequence is offered by a teacher for acquisition of a specific course based on the pedagogical experience of the teacher and links between topics. Learner topic sequence is created from the learner-chosen topics during the course acquisition based on links between topics that the author/teacher has previously indicated. Optimal topic sequence is based on the learning process data and links between topics of the all previous learners in the course.

Optimal topic sequence is created using the optimal topic sequence creation method using links between the course topics, the topic sequences used by previous learners (who have studied the course), and the obtained results (grades) of the course. To obtain optimal topic sequence, learner topic sequences that meet the criteria of having the best results of the course are selected. Then, it is assumed that the optimal topic sequence creation method determines the most appropriate topic sequence of the course, i.e. topic sequence that will help to achieve the best results of the course. Optimal topic sequence creation method is published in the paper (Vagale and Niedrite, 2016a)

Topic sequence organization method, developed for this purpose, provides the opportunity to use the variants for the topics sequence realized in the system. The course topic sequence organization method is published in the paper (Vagale and Niedrite, 2016b). The implementation of the adaptation model is described in the Section 4.4. 


\section{System Implementation}

\subsection{Overview of the System Implementation}

In the development of the LMPAELS, a three-layer client-server architecture is used with the following layers: (a) the data layer, (b) the application layer, and (c) the client layer (see Figure 2). The specified architecture is consistent with the multi-layer architecture that is typical for server-side web-based applications.

The data layer includes a data repository consisting of SQL supporting relational databases Moodle DB (WEB, d) and LMPAELS DB. The application layer consists of the web and application servers. The application server runs Moodle with an implemented component to provide the adaptation. The client layer contains devices running a web browser. This layer provides a system client interface that interacts with the LMPAELS. Clients of the system are a learner, a teacher, a course developer, a course manager, and a system administrator.

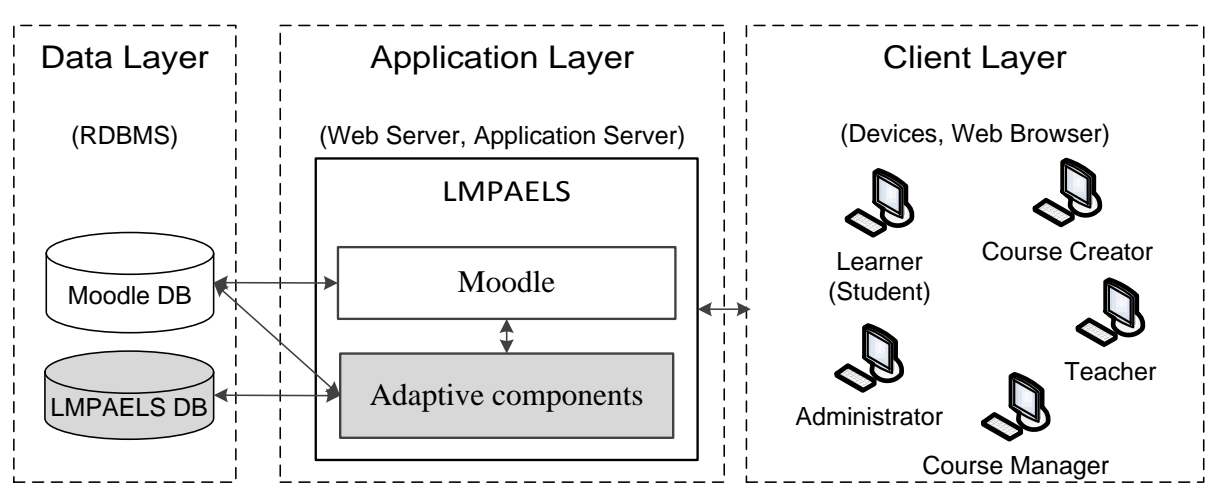

Figure 2. The three-layer architecture of the LMPAELS.

Learning management system Moodle serves as the basis for the development of LMPAELS (see Figure 2). Moodle (www.moodle.org) is distributed using the GNU GPL (General Public License) v3 license. The choice of Moodle is based on the fact that this system is one of the most popular open source learning management system (Caputi and Garrido, 2015). Moodle includes simple personalization opportunities, but it is not intended to use it for content adaptation (Limongelli et al., 2011). Moodle consists of separate modules that make it easily adaptable and extendable.

To ensure the performance of the LMPAELS system, Moodle provides user authentication, creation of the learning courses, and ensures the use of various types of learning resources and activities (WEB, c). Additional components (modules, data repositories) that are necessary to ensure the LMPAELS learner model, content model, and adaptation model have been created in Moodle system.

Figure 3 shows the components implemented in each one of the modules of the LMPAELS system. The arrows indicate the direction of the data flow between the components. These components were implemented using the following web programming technologies: PHP, JavaScript, JQuery, HTML, and CSS. With the help of SQL, the tables for storing missing data were created, data acquisition and recording into 
tables was implemented. Each one of the LMPEALS model realizations is described below.

\subsection{Learner Model Implementation}

Two new modules were created as the part of LMPAELS learner model: learner data acquisition module and learner data management module (see Figure 3). Learner data storage is used for storing data about the learner.

The learner data acquisition module provides acquisition of learner's data (Testing, Data import, Data collection etc.) (see Figure 4).

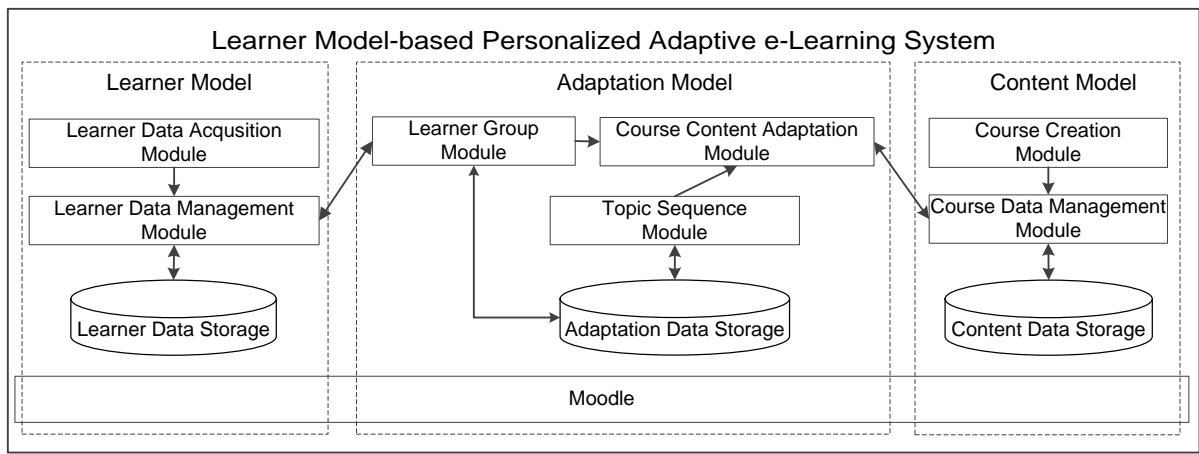

Figure 3. The interaction of the LMPAELS system components.

Data for the learner model in the system can be obtained using (a) a system user profile, (b) results of surveys and quizzes, (c) individual choices of the learner, (d) an event $\log$, (e) a user group in the system that the learner has been classified, (f) an external system. Types of data mining for the learner model are described in details in (Vagale and Niedrite, 2014). An external ePortfolio system Mahara is used to obtain the initial data about the learner. Retrieving data from the ePortfolio system is described in (Vagale, 2013).

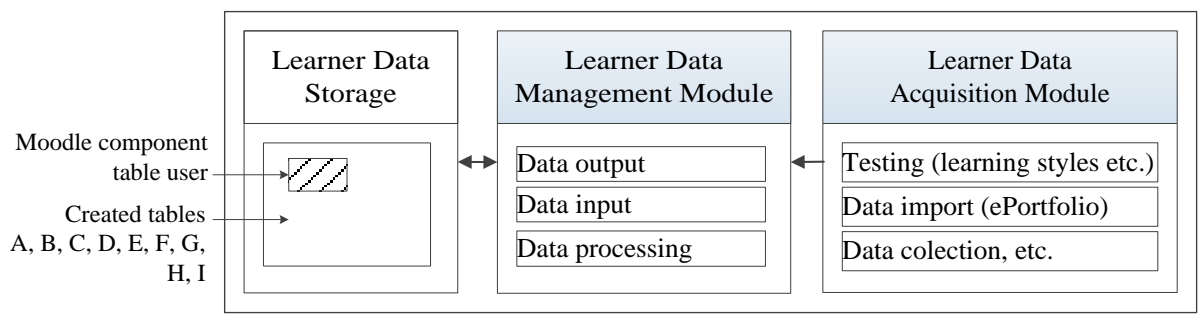

Figure 4. The architecture of the learner model of the LMPAELS.

The learner data management module allows to view, input and process data (Data output, Data input, Data processing) about the learner (see Figure 4). 
The storing of the learner data is performed using learner data storage. It includes data from Moodle DB table user and additionally created tables. The Moodle database table user stores only the standard data about system's users. These data describe the personal data of the created system only partially, therefore nine additional tables were created (tables A, B, C, D, E, F, G, H, I) (see Figure 4). The newly formed tables store obtained (unprocessed) data about the learner and the type of these data acquisition; data about the learner's experience with e-learning system usage; system's settings indicated by the learner (preference data); data about the equipment used during the learning process, learner's learning style, previous knowledge, and the level of difficulty of the course; and data acquired during the learning process. Additional tables ensure the storing of data necessary for the learner model, corresponding to the eight data categories described in the learner model (see Section 3.1).

\subsection{Content Model Implementation}

For implementation of the LMPAELS content model, many of the components existing in Moodle that are used in the Moodle course organization, such as course structure modules, sections, activities and resources are used (WEB, d). In addition, a course creation module and a course data management module were created (see Figure 3). Content data storage was developed for storing content model data.

The course creation module is responsible for creating course content, content elements (resources and activities), and their relevance to the type of adaptation (see Figure 5). By adding a new resource/activity, the author of the course indicates the relevance of this content element to the type of adaptation of the course content (learning style, course difficulty level, and background knowledge).

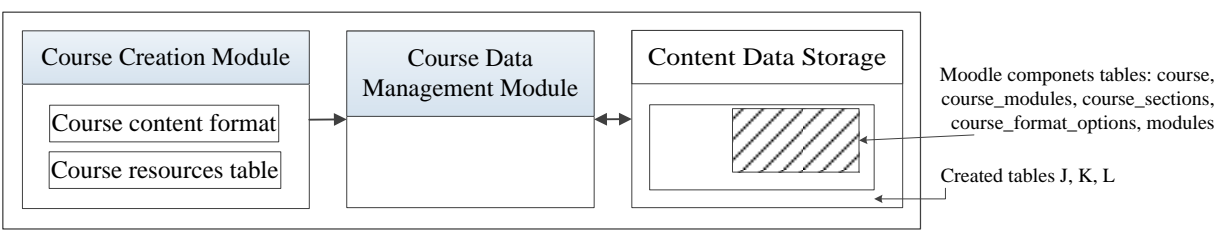

Figure 5. The architecture of the content model of the LMPAELS.

Course data management module provides content model data storage, processing and output.

Storing of the content model necessary data is ensured by content data storage. It is developed combining Moodle system course describing tables (course, course_modules, course_sections, course_format_options, modules) and three additional tables (Created tables J, K, L) (see Figure 5). New tables contain data about course topic parts, resources used in the section and their types.

Implementation of the course structure is provided by the Moodle course format. In the beginning of the new course, the course author specifies the course type (theoretical or practical). The system creates a course structure according to the choice made. For example, Figure 7 shows the structure of the topic "Data output" (Datu izvads) of the practical course " Programming Foundations I". The topic consists of only one learning object that has four parts: description part (Topic Summary), theoretical part (Theory), practical part (Practice), and evaluation part (Evaluation). 


\subsection{Adaptation Model Implementation}

The three modules created for the implementation of the LMPAELS adaptation model are: (i) the learner groups module, (ii) the topic sequence module, and (iii) the course content adaptation module (see Figure 3). Adaptation model data are stored in the adaptation data storage.

Fig. 6. shows the data flow between the adaptation model components and adaptation types that are implemented in the system: course structure (Course type), course content (Content adaptation type), and course topic sequence (Topic acquisition sequence). The figure represents which adaptation type is used by every one of the implemented modules.

The learner group module provides (i) the creation of learner groups in the course, (ii) the creation of adaptation scenarios for each learner group, (iii) the classification of learners in existing learner groups. The learner group classification method is used to create learner groups. The learner group identificator searching algorithm is used to classify learners in the existing learner groups.

The topic sequence module provides the organization of topic sequences (see Figure 6). The main tasks of the topic sequence module are collecting data from the learning process, creating the optimal topic sequence of the course, and topic sequence management. The optimal topic sequence creation method is used to create the recommended topic sequence. The topic sequence organization method is used for the topic sequence organization.

The course content adaptation module implements the adaptation scenario for the learner. The course content adaptation module finds the group number assigned to the learner and the adaptation scenario of this group. Subsequently, according to the description of the scenario, it adapts the course content.

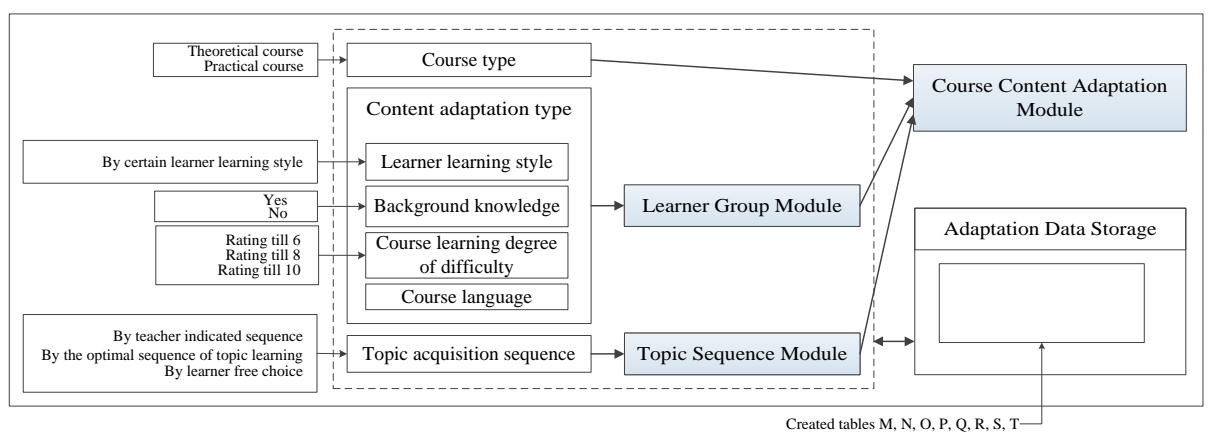

Figure 6. The architecture of the adaptation model of the LMPAELS.

Storing of the aforementioned adaptation model components data is done in adaptation data storage. Multiple tables were created to ensure the learner group module performance (Created tables M, N, O, P, Q, R, S, T) (see Figure 6). They store features lists used for adaptation, values of each feature, learner groups created in every course and their descriptions, lists of course learners and their learner group identificators and adaptation scenario of every learner group. Two new tables were created for topic sequence module that store course acquisition parameters (links between topics, teacher 
topic sequence and optimal topic sequence), and previous learners used topic sequences and grades.

In the learning systems, adaptation is organized according to three levels: content, presentation (portrayal), and navigation levels (Baumeister et al., 2005; Bunt et al., 2007). There are many adaptation techniques available for each one of these levels. The use of adaptation techniques for the adaptation of course content elements in the adaptive e-learning systems ("V") and the developed system ("S") are summarized in Table 1. The first column of the table indicates the level of adaptation. The second column shows the adaptation techniques used at each level. The following columns indicate to different parts of the learning object (LO) of the developed system's content model and the adapted elements. A column with the letter "V" denote the use of adaptation techniques in the adaptation of content elements in the existing adaptive elearning systems. The column with the letter "S" indicates the techniques used in the practical implementation of the developed system. The sign " + " denotes the use of a particular technique.

Table 1. The content element adaptation techniques for the adaptive e-learning systems ("S") and the developed system ("V").

\begin{tabular}{|c|c|c|c|c|c|c|c|c|c|c|c|}
\hline \multirow[t]{3}{*}{$\begin{array}{l}\text { Adaptation } \\
\text { level }\end{array}$} & \multirow[t]{3}{*}{$\begin{array}{l}\text { Adaptation } \\
\text { technique }\end{array}$} & \multicolumn{4}{|c|}{$\begin{array}{c}\text { LO } \\
\text { theoretical } \\
\text { part } \\
\end{array}$} & \multirow{2}{*}{\multicolumn{2}{|c|}{$\begin{array}{c}\text { LO } \\
\text { practical } \\
\text { part }\end{array}$}} & \multicolumn{4}{|c|}{$\begin{array}{c}\text { LO } \\
\text { assessment } \\
\text { part }\end{array}$} \\
\hline & & \multicolumn{2}{|c|}{ Content } & \multicolumn{2}{|c|}{ Explanation } & & & \multicolumn{2}{|c|}{ Task } & \multicolumn{2}{|c|}{ Test } \\
\hline & & $\mathbf{V}$ & $\mathbf{S}$ & $\mathbf{V}$ & $\mathbf{S}$ & $\mathbf{V}$ & $\mathbf{S}$ & V & $\mathbf{S}$ & V & $\mathbf{S}$ \\
\hline \multirow{9}{*}{$\begin{array}{l}\text { Content } \\
\text { level }\end{array}$} & Content variants & + & + & & & + & & + & & + & \\
\hline & Additional explanations & & & + & + & & & & & & \\
\hline & Prerequisite explanations & & & + & & & & & & & \\
\hline & Comparative explanations & & & + & & & & & & & \\
\hline & Explanation variants & & & + & & & & & & & \\
\hline & Conditional fragments & + & + & & & + & + & + & + & + & + \\
\hline & Stretch text & + & & & & & & & & & \\
\hline & Fragment variants & + & & & & + & & + & & + & \\
\hline & Sorting fragment & + & & & & + & & & & & \\
\hline \multirow{2}{*}{$\begin{array}{c}\text { Presentation } \\
\text { level }\end{array}$} & Layout variants & + & & + & & + & & + & & + & \\
\hline & The use of multiple languages & + & & + & & + & & + & & + & \\
\hline \multirow{12}{*}{$\begin{array}{c}\text { Navigation } \\
\text { level }\end{array}$} & Global guidance & + & + & & & + & + & + & + & + & + \\
\hline & Local guidance & + & + & & & + & + & + & + & + & + \\
\hline & Global orientation support & + & + & & & + & + & + & + & + & + \\
\hline & Local orientation support & + & + & & & + & + & + & + & + & + \\
\hline & Personalized views & + & & & & + & & + & & + & \\
\hline & Link direct guidance & + & + & & & & & & & & \\
\hline & Link sorting & + & & & & & & & & & \\
\hline & Link annotation & + & & + & & & & & & & \\
\hline & Link removal & + & & & & & & & & & \\
\hline & Link hiding & + & + & + & + & & & & & & \\
\hline & Link generation & + & & & & & & & & & \\
\hline & Content map adaptation & + & + & & & & & & & & \\
\hline
\end{tabular}


Table 2 summarizes the adaptation techniques for the navigation elements that are used for the course topic sequence organization - the management of the links between topics. Figure 7 shows an example of a "Data Output" topic interface of the "Programming Foundations I" course. The figure shows how a "teacher" role user sees this topic.

Table 2. The adaptation techniques of the course topics sequence management for the adaptive elearning systems ("S") and the developed system ("V").

\begin{tabular}{|c|l|c|c|}
\hline Adaptation level & \multicolumn{1}{|c|}{ Adaptation technique } & V & S \\
\hline \multirow{5}{*}{ Navigation level } & Link direct guidance & + & + \\
\cline { 2 - 4 } & Link sorting & + & + \\
\cline { 2 - 4 } & Link annotation & + & \\
\cline { 2 - 4 } & Link hiding & + & + \\
\cline { 2 - 4 } & Link removal & + & \\
\cline { 2 - 4 } & Link generation & + & + \\
\cline { 2 - 4 } & Content map adaptation & + & + \\
\hline
\end{tabular}

\section{1. tēma (Datu izvads)}

\begin{tabular}{|c|c|}
\hline \multicolumn{2}{|l|}{ TOPIC SUMMARY } \\
\hline \multicolumn{2}{|c|}{ levads programmēsanas valodā C++. Programmas struktūra. Funkcija main(). Datu izvads. Komentāri. } \\
\hline \multicolumn{2}{|l|}{ THEORY } \\
\hline 'Rs: *levads kursā & vDatu izvads \\
\hline 'PE. *Programmas struktūra & i. rProgrammas struktūra (EN) \\
\hline 'BS. *Datu izvads & rlevads \\
\hline 'pis *Izvada noformēšana & 2) rPar programmas struktūru \\
\hline wC++ Beginners Tutorial $1(\mathrm{EN})$ & AProgrammas struktūra \\
\hline wDev C++ input/output tutorial & kIzvads \\
\hline vProgrammas struktūra, datu izvads & OProgrammēsanas valoda ir .... \\
\hline vDatu izvads & OC++ir ... \\
\hline \multicolumn{2}{|l|}{ D PRACTICE } \\
\hline \multicolumn{2}{|l|}{ 1lemācities programmas struktūru } \\
\hline \multicolumn{2}{|l|}{ 2lemācīties programmas struktūru } \\
\hline \multicolumn{2}{|l|}{ 3lemācīties programmas struktūru } \\
\hline \multicolumn{2}{|l|}{ EVALUATION } \\
\hline \multicolumn{2}{|l|}{$\nabla_{2 \text { Tests1 }}$} \\
\hline \multicolumn{2}{|l|}{ 1Tests1 } \\
\hline 3Tests1 & \\
\hline
\end{tabular}

Figure 7. An example of the teacher role interface for the topic "Data output" of the practical course "Programming Foundations I". 
Theory section includes resources for learning a specific topic. The first symbol in the name of each resource indicates the learning style or explanation. The "*" symbol indicates that the resource will be displayed to all learners (with any learning style), such as "*Introduction to the course". The "v", "r", "a", "k", and "w" symbols indicate the learning style - visual, aural, read, kinaesthetic, and visual-aural style combination respectively. The symbols " 0 " and " 1 " indicate absence or existence of the preknowledge of the course respectively. In the Practice and Evaluation sections, the first symbol of the activity name indicates the learning difficulty level: symbol "1" - the lowest, "2" - the average, and "3" - the highest degree of difficulty.

Different learners (with the "student" role) will see the topic differently. For example, a learner who has a visual LS, has no pre-knowledge and has the highest learning difficulty level will see the resources and activities that contain "*", "v", "0", and "3" symbols as the first in the activity name.

\section{Experiment}

An experiment was conducted to test the developed system. The system was approbated in Daugavpils University (Latvia) during the learning process. In the fall semester of the study year 2016/2017, the course "Programming Foundations I" (first study year) was tested. In the spring semester, the course "Databases II" (second study year) was tested. Two versions of both courses (adaptive and non-adaptive) were prepared.

The experiment was organized in a particular institution where the number of students was not sufficient to organize a proper experimentation. Therefore, participants of the experimental study had the opportunity to use both versions of adaptive and nonadaptive courses. In the case of a proper experiment, one learner group would use only the adaptive course and the second group would use only the non-adaptive course.

The goal of the experiment was to evaluate the architecture and functionality of the developed system, and to determine the target audience that finds the system suitable.

\subsection{Participants of the Experiment}

Forty-six students of the professional bachelor study program "Information Technologies" participated in the approbation and evaluation of courses. 20 of them were in their first year of studies and the remaining ones were in their second year of studies.

$31(67 \%)$ respondents were men and $15(33 \%)$ - women. $37(80 \%)$ respondents have obtained general secondary education and $9(20 \%)$ - a secondary vocational education. $22(48 \%)$ respondents have the working experience with Moodle for less than 1 year and $24(52 \%)$ respondents have used it for more than a year. $29(63 \%)$ respondents have the experience of using other e-study systems, but 17 (37\%) have no experience with other e-learning systems. The IT competence of $6(13 \%)$ respondents was rated as high, for 34 $(74 \%)$ as medium, and for $6(13 \%)$ respondents as low.

\subsection{Description of the Courses of the Experiment}

In the adaptive course "Programming Foundations I", 10 topics were proposed (topic numbers are indicated in parentheses): (1.) "C++ program structure. Data Output", (2.) 
"Data Types. Data Input", (3.) "Mathematical Functions", (4.) "Conditional constructions", (5.) "User-defined functions", (6.) "Parametric functions", (7.) "Cyclic constructions", (8.) "One-dimensional numeric arrays", (9.) "Multi-dimensional numeric arrays", and (10.) "Symbolic arrays". Both the links between the topics and the teacher topic sequence corresponding to the above-mentioned topic numbers were defined.

The course "Programming Foundations I" was tested twice. The first time, the course was used to test optimal TS methods and TS organization method in the study year 2015/2016, where the optimal topic sequence obtained in the experiment was OTS $=\{1,3,5,7,8,9,10,2,4,6\}$ (Vagale and Niedrite, 2016a). The second time, in the course of approbation of the experimental system, the acquired OTS was offered to learners as the optimal topic sequence of the course. The reuse of the course "Programming Foundations I" gave an opportunity to evaluate optimal TS method in action.

In the adaptive course "Databases II" 7 topics were offered (topic numbers are indicated in parentheses): (1.) "Introduction", (2.) "Stored procedures", (3.) "Stored functions", (4.) "Triggers", (5.) "Events", (6.) "Transactions", (7.) "PHP and MySql". Both the links between the topics and the teacher topic sequence corresponding to the mentioned topic numbers were defined. As the course "Databases II" is used for the first time, by default the optimal topic sequence equals the teacher topic sequence.

\subsection{Description of the Survey}

Each student used both the adaptive and non-adaptive version of the course. After finishing studying the adaptive and non-adaptive course, students were encouraged to compare and evaluate both of the course versions. Each learner completed the course evaluation survey electronically, and the system saved the data obtained in the database. SPSS software was used to process the obtained data.

A survey consisting of two parts was created for obtaining data about the course. The first part contains 8 questions about the respondent. The second part contains 46 statements about the course. The statements were grouped into five groups (scales) that were used as course evaluable characteristics: course relevance (10 statements), course cognitive rating (10 statements), course structure (7 statements), course content (6 statements), and course topic sequence (12 statements).

The scale "E-course relevance" describes the benefits of using the course. The scale "E-course cognitive rating" describes the course usability. The scale "E-course structure" is used to evaluate the structure of the content model used in the creation of the course. The scale "E-course content" helps to evaluate how much the content of the topic is suitable to the learner characteristics. The scale "E-course topic sequence" is evaluating the topic sequence variants offered in the system.

The choice of scales was determined by the methods implemented in the experimental system. Each scale was used in both the adaptive and non-adaptive course evaluation. A total of 10 measurements (five adaptive course and five non-adaptive course scales measurements) were obtained. The 5-point Likert scale was used to evaluate each statement in the survey. All statements have equal weight. 


\subsection{Results Evaluation}

To identify the target audience to the respondents of which the implemented methods in the LMPAELS have been applied, an analysis of the assessments of each respondent's adaptive and non-adaptive course was conducted. For this purpose, a two-stage cluster analysis was used aiming at bringing together the most interrelated learners in groups and getting homogeneous groups to understand how similar the grouped learners are. Analysis of the isolated groups allowed studying the links between the various phenomena parameters at a much higher level.

As a result of cluster analysis, two groups of respondents were identified. The first group included 31 respondents or $67.4 \%$ of all respondents. The second group included 15 respondents representing $32.6 \%$ of all respondents.

Both groups of respondents rated the adaptive course higher than the non-adaptive one, moreover, the first group rated the adaptive and non-adaptive course higher than the second group. Differences between the adaptive and non-adaptive course scales for respondents in the first group are small, which means that respondents from the first group do not see the difference between the adaptive and non-adaptive course.

Respondents in the second group rated the adaptive and non-adaptive course differently. Adaptive (A) course average arithmetic mean ( $\bar{x})$ assessments are significantly higher than those of the non-adaptive $(N)$ course. The scale "e-course relevance" ( $\mathrm{A} \overline{\mathrm{x}}=3.387, \mathrm{~N} \overline{\mathrm{x}}=2.827)$ and the "e-course cognitive evaluation" (A $\overline{\mathrm{x}}=3.412$, $\mathrm{N} \overline{\mathrm{x}}=2.903$ ) have lower indicators of the assessments of the adaptive course than in the first group, while the scales "e-course structure" (A $\bar{x}=3.876, N \bar{x}=3.267), "$ E-course content" (A $\bar{x}=3.622, N \bar{x}=3.011)$, and "E-course topic sequence" (A $\bar{x}=3.644, N$ $\overline{\mathrm{X}}=2.828$ ) almost reach level of the first group. These differences in the adaptive and nonadaptive course evaluations indicate that the second group spots the differences between the adaptive and non-adaptive courses.

Kolmogorov-Smirnov test and Shapiro-Wilk test results show that the empirical distribution of both respondent groups corresponds to the normal distribution $(p>0.5)$ with a reliability of $95 \%$. By analysing scale measurements for each group of respondents with the T-test for related samples, it was concluded that for the first group differences in scales in pair assessments are not statistically significant $(0.143 \leq p \leq 0.903$, where $\mathrm{p}$ is the significance level value), but for the second group differences in scales for assessments are statistically significant $(0.001 \leq \mathrm{p} \leq 0.007)$.

The difference between the adaptive and non-adaptive course assessment scores for the second group is significantly higher than for the first group, and the differences in scale measurements are statistically significant. Therefore, the second group of respondents is a target audience. That means that the participants of the second group were able to evaluate the functionality offered in the adaptive course.

A more in-depth analysis of the respondents included in the second group was conducted. The second group (15 students in total) consists of $60 \%$ (9) of the first-year students and $40 \%$ (6) of the second-year students. Group composition by gender is $60 \%$ (9) men and $40 \%$ (6) women. $80 \%$ of respondents have general secondary education and $20 \%$ have vocational secondary education. $60 \%$ (9) of the second group have experience in using learner management system. $53.33 \%$ (8) of respondents began to use Moodle for organizing the study process only during the last year. 46.67\% (7) have Moodle experience that exceeds 1 year. By the level of IT competence, the higher percentage of 
students $73.33 \%$ (11) has an average level of skills. The percentage of the high and low level of IT competence in each category is $13.33 \%$ (2) of the respondents.

\section{Discussion}

The development of an adaptive course described in this paper requires a lot of time. During the development of adaptive course material for the system developed in the course of the research, most of the time was consumed to create learning resources in accordance with the content model (see Section 3.2), i.e. in the complete set one resource is created in five different variants according to the learning style (visual, aural, reading, kinaesthetic, or visual-aural) (see Section 3.3).

In order to reduce the time required for the development of an adaptive course, most of the resources and activities (or even all) used in the non-adaptive e-learning course can be used in the adaptive course, and later the course can be supplemented with new resources and activities tailored according to learner's characteristics.

Due to the large amount of time needed for the development of the adaptive course, the experimental system is designed so that the resource in the adaptive course can be added and shown to the learners with any learning style (the first symbol in the resource name should be "*") (see Figure 7). Thus, in the adaptive course topics, it is also possible to use study materials from a non-adaptive course and each learner is provided with study materials in the case when it is not possible to create a learning material of a particular learning style for some topic. Creating tests also takes a lot of time, so an approach where in a test of a higher level of complexity some/all questions from a test with a lower level of complexity can be used.

In accordance with the implementation of the adaptive e-learning environment, the minimum set of study materials for the theoretical course may be as follows: to take materials from a non-adaptive course for each topic and offer them to all learners and to create three compulsory tests with a low, medium, and high level of complexity. The minimum set of study materials for practical course topics in the subject may be the following: theoretical materials may or may not be included, in the practical part there are tasks with a low, medium, high level of complexity, and in the part of the assessment, three tests are required according to each level of complexity.

The use of the developed system pays off when (i) learning materials for nonadaptive systems have already been prepared; (ii) the course organizes groups of learners by features with a small number of values (e.g. only by the existence/absence of preknowledge or only by the degree of difficulty of the course), (iii) courses that require a high individual time consumption are taught.

\section{Conclusions}

Architecture of the personalized adaptive e-learning system proposed in the paper was successfully tested in an empirical study. Results of the study showed that Moodle, which was taken as the basis of the developed architecture of the system, was a correct choice because it provided many functions necessary for functionality of the LMPAELS system. The result is a solution that can quickly create a personalized adaptive e-learning system suitable for learners' needs. The research has a practical meaning in solving 
Moodle adaptation issues. Architecture of the personalized adaptive system can be applied to the learning management system with topics in the course structure.

Methods used to provide adaptation improved the system's functionality and were also evaluated by the learners. A more detailed analysis of the approbation results is the subject of a new paper. The purpose of the data analysis in this paper was to identify those learners who perceive the differences between an adaptive and non-adaptive course. As a result, respondents whose differences in evaluations of both courses are statistically significant were identified. The developed system is particularly suitable for the respondent with the following characteristics: first study year female students with general secondary education, average level of IT competence, with learning management system usage experience and Moodle usage experience less than a year. The described learner belongs to the "sensitive" learner category for the acquisition of programming courses.

The experiment had some limitations. In the experiment, only two adaptive courses were used. The results of the evaluation of the developed system are based on a small number of learner evaluations. Programming courses were used for the system approbation, but the system is also suitable for other theoretical and practical courses.

Future research covers (i) conducting an in-depth evaluation of the developed system by increasing the number of learners using different categories of respondents using courses in various fields including theoretical courses, (ii) developing an approach for automatic determination of the learning style, (iii) determining the learners that need an additional support and provide support for them.

\section{References}

Alshammari, M., Anane, R., Hendley, R. J. (2015). An E-Learning Investigation into Learning Style Adaptivity. In: HICSS-48, pp. 11-20. Hawaii, USA.

Allen, C. A., Mugisa, E. K. (2010). Improving Learning Object Reuse Through OOD: A Theory of Learning Objects. Journal of Object Technology 9(6), 51-75.

Ahmed, M. U., Sangi, N. A., Mahmood, A. A. (2018). Model of Adaptive E-Learning in an ODL Environment. Mehran University Research Journal of Engineering and Technology, 37(2), 367-382.

Bunt, A., Carenini, G., Conati, C. (2007). Adaptive content presentation for the web. In: The adaptive web. Heidelberg: Springer, pp. 409-432.

Baumeister, H., Knapp, A., Koch, N., Zhang, G. (2005). Modelling adaptivity with aspects. In: International Conference on Web Engineering. Heidelberg: Springer, pp.406-416.

Caputi, V., Garrido, A. (2015). Student-oriented planning of e-learning contents for Moodle. Journal of Network and Computer Applications 53, 115-127.

Hart, L.E. (2015). Introduction to model-based system engineering (MBSE) and SysML. In: Delaware Valley INCOSE Chapter Meeting. New Jersey.

Limongelli, C., Sciarrone, F., Vaste, G. (2011). Personalized e-learning in Moodle: the Moodle_LS System. Journal of e-Learning and Knowledge Society 7(1), 49-58.

Prensky, M (2001). Digital natives, digital immigrants Part 1. On the horizon 9(5), 1-6.

Riad, A., El-Minir, H., El-Ghareeb, H. (2009). Review of e-Learning Systems Convergence from Traditional Systems to Services based Adaptive and Intelligent Systems. Journal of Convergence Information Technology 4(2), 108-131.

Scheuermann, F., Pedró, F. (2010). Assessing the effects of ICT in education: Indicators, criteria and benchmarks for international comparisons. Joint Research Centre-European Commission.

Tosheva, S., Stojkovic, N., Stojanova, A., Zlatanovska, B., Martinovska Bande, C. (2017). Implementation of adaptive" E-school" System. TEM Journal 6(1), 349-357. 
Vagale, V. (2013). Eportfolio Data Utilization in LMS Learner Model. In: Hammoudi, S., Maciaszek, L., Cordeiro, J., Dietz, J. (eds.) ICEIS 2013, vol. 2, pp. 489-496. SCITEPRESS, Portugal.

Vagale, V., Niedrite, L. (2012). Learner Model's Utilization in the E-Learning Environments. In: C̆aplinskas, A., Dzemyda, G., Lupeikiene, A., Vasilecas, O. (eds.) BALTIC DB\&IS 2012, Local Proceedings, Materials of Doctoral Consortium, pp. 162- 174. Žara, Vilnius.

Vagale, V., Niedrite, L. (2014). Learner Group Creation and Utilization in Adaptive E-Learning Systems. In: Frontiers in Artificial Intelligence and Applications, Databases and Information Systems VIII, vol. 270, pp. 189-202. IOS Press.

Vagale, V., Niedrite, L. (2016a). The Application of Optimal Topic Sequence in Adaptive eLearning Systems. In: Arnicans G., Arnicane, V., Borzovs, J., Niedrite, L. (eds.) Baltic DB\&IS 2016, CCIS, vol. 615, pp. 352-365. Springer, Heidelberg.

Vagale, V., Niedrite, L. (2016b). The Organization of Topics Sequence in Adaptive e-Learning Systems. In: Frontiers in Artificial Intelligence and Applications, Databases and Information Systems X, vol. 291, pp. 327-340. IOS Press.

Vagale, V., Niedrite, L., Ignatjeva, S. (2018). The Architecture of the Personalized Adaptive ELearning System. In: Lupeikiene A., Matulevičius R., Vasilecas O. (eds.), Baltic DB\&IS 2018 Joint Proceedings of the Conference Forum and Doctoral Consortium, vol. 2158, pp. 114-123.

Vassileva, D. (2012). Adaptive E-Learning Content Design and Delivery Based on Learning Styles and Knowledge Level. Serdica Journal of Computing 6(2), 207-252.

WEB (a) Communication from the Commission to the Europian Parliament, the Council, the Europian Economic and Social Committee and the Committee of the Regions, https://eurlex.europa.eu/legal-content/EN/TXT/PDF/?uri=CELEX:52013DC0654\&from=EN.

WEB (b) Educational development Guidelines 2014-2020, https://m.likumi.lv/doc.php?id=266406.

WEB (c) Moodle developer documentation https://docs.moodle.org/dev/Main_Page.

WEB (d) Moodle DB schema, https://docs.moodle.org/dev/Database_schema_introduction

Received November 28, 2019, accepted April 29, 2020 